\title{
EMPLOYABILITY SKILLS-A STUDY ON THE PERCEPTION OF THE ENGINEERING STUDENTS AND THEIR PROSPECTIVE EMPLOYERS IN INDIA
}

\author{
Dr. Tarananum \\ Post-Doctoral Fellow, ICSSR \\ Dr. Mohammad Junaid Alam \\ Faculty, School of Business Studies, Sharda University
}

\begin{abstract}
This paper aims at studying the perception of Employers along with the employees regarding the employability skills required by the Entry level engineering graduates to possess for getting employed in the Multinational Software Companies. It seems to be an experimental study. For evaluating the perception of skill set required by the engineering graduates and their employers, two sets of questionnaires were developed by the researcher. The data was collected and its study revealed the significant differences between the opinion (perceptions) of the graduates and the employers. It is the disparity which makes the graduates prone to less likely to be employable to various MNCs requiring the software skills. The Indian Engineers' Employability skills haven't been into light in terms of its literature and research. The available study reveals the perception from the employers' sides. This paper covers both the graduates' as well as employers' perception regarding the employability skills they have and the skills which are required.
\end{abstract}

Keywords: Engineering Graduates, Perception,Employability,Employers,

\section{Introduction:}

The highly technical as well as the sophisticated jobs at present require the skills of the employees accordingly. The transformation of orientation of the jobs from being the output oriented to service oriented has resulted in the increment of the demand of the professional employees in the engineering sector both with the technical as well the behavioral skills (HillageJ,1999).Certain companies or organization allure their work force to incur more talent in them by various methods of recruitments. The direct recruitment of the students from the engineering colleges is one such incentive(Harvey,2000). The notion behind this is that the graduates passing out from the engineering colleges have a better hold on the subject knowledge (Knight '2002). The graduate with technical content in mind as well as with the pleasing personality is like a boon for the organization(Forbes,2004).A number of employability skills models were plotted by various scholars in UK (1980s), in Europe (1990s)and in Australia (2000). The models provide equal weightage to both the personal attributes as well as the technical do over of the graduates for both are mandatory for creating even trivial piece of program (software 
skills).Merely attaining the jobs doesn't complete the meaning of 'Employability' as said by Atkinsin 1999rather, the term deals with the extent to which an engineering professional invests his professional gain over for the betterment of the society by the means of his innovation and practice as mentioned in the Employability skills for Australian industry; Literature review and frameworkdevelopment,2001.The engineering curricular holds the decisive aim of producing the engineering skilled force who would respond to the societal needs with best technical and behavioral skills(HassanB,2007).Only those attributes will be focused on by the employability skills which aid an Engineer to develop his technical content in his mind.

\section{Background and Scope of the Study:}

Most of the developed countries face a major challenge of Global Ageing of the work force (World population ageing1950-2050,2002).It not only affects the technical, educational and social factors but also rapidly transforms the employment trends of both the developed and developing countries as says the Worldpopulationageing,2009).A study has been conducted by the World Economic Forum related to the prediction of the extent of talent shortage in the upcoming decades. The UN estimation says that Japan would be in a needtoadmit647,000immigrantsannuallyfor thenext50yearsfor the sake of setting the benchmark of its working population size to the level 2000as per the report of the Replacementmigration,2009.Unless the immigration policies are liberalized or the manufacturing or service-related industries are shifted oversees the significant labour shortage shall not show any downfall. The majority of developed nation possess certain unlawful approach regarding the immigration. They totally focus on the product automation and services though it is immaterial to do so for the automation in the service jobs can only be up to $13.5 \%$.

\section{Status of Employability Skills of Graduates in India:}

India stands among the emerging markets of the world.The change of the nation from being an agrarian one from that of being the industrialized one is only adhered due to the labour shortage as mentioned in the reports of 'The employability

skillexpansionlandscapeinIndiaandimpleme ntingquality skilltraining ofthe month of August2010.Though with enough human capital to invest in the global talent market, yet the ultimate strong employability challenge has become the tailback of the nation to do so especially in front of the engineering graduates(Talentshortagesurvey'2005),(Gl obal talent risk-sevenresponses'2011).Even 400,000 engineers are produced on annual basis in India yet the corporations find it difficult to pick up the ones with the required technical skills(Replacementmigration,2009). The estimations of the Indian Association of Software Services Companies reveal that around 500,000 potential engineering professionals will see their downfall in a single year (2010) (Talentshortagesurvey,2005).Several studies were conducted in India to judge the employability skills of the students here. The study show that the percentage of Indians being unemployable is $75 \%$ (Talent shortagesurvey,2005).This rises the 
disputes like it doesn't show up the actual status of the pass-outs in India or it is obsolete and else. But the recent research from the World Bank reveals that the $64 \%$ of the employers have shown an average satisfaction from their recruits as per the report of Andreas Blom of 2011).About $34 \%$ of the employers from the world find it hard to make up the gap of talent but in our country around $67 \%$ of them aren't able to find the right talent required for their institute (from both Arts and Science sides)(Talentshortagesurvey,2005). The speculations clearly alarms for the requirement of the appropriate cognizance and training for the pass-outs.

\section{Major Objectives:}

The study solely focuses on revealing the job skills of the engineering pass-outs from India. This paper targets the skill gap of the section wishing to join the software companies. It was written on the basis of the data of the pilot study of the research. For this the author has deployed in the major employability models of various developed nations such as Japan (Nguyen. DanhNguyen'2005), Australia (HillageJ'1999), Malaysia (Azami zaharim'2009) and also the framework developed by World Bank (AndreasBlom'2011).

\section{The following are the objectives of the study}

- To judge the perception of the employers regarding the employability skills.

- Identifying the attitude of the Engineering alumnae regarding these skills.

- To ascertain and bridge the gap between the perceptions obtained from the groups of the first two points.
- Recognizing whether or not the gender (male and female) and the experience affect the employability skills of an individual.

Though witnessing a lot of studies dedicated to the employers' perception solely, the author has assigned due importance to graduate's perception and attribute also. The study also considers the factors like the gender and the work experience.

\section{Research Design:}

This study is an examining one. The author has got to develop a total of 02 questionnaires with separate skill frame work and has found a set of skills for skill inventory. The classification of the skill set was done on the pattern of developed model from the World Bank to measurer the employability skills of the Indian graduates from engineering (AndreasBlom,2011).A total of 120 respondent (students) have dedicated their part in the survey; All those from the graduate or post-graduate final year. The graduate students hold the response rate of $75 \%$ i.e. $90 / 120$. The author has also regarded the employers' perception on the employability skills. Around 60 professionals were reported as employers and among them only 35dedicated their part in the survey. The employers' response rate gave the reading of $58 \%$. The sampling aids like clustered and snow bowl types were put to aid the survey.

\section{Major Findings and Results:}

The findings enlighten the views of employers as well as the students about the job skills. The reports of the survey clearly identifies that the employers look for the personal and behavioral traits within the students while the students think of developing only the technical skills 
forgetting about anything else.In addition to the aforesaid findings, the perception shows a huge contrast between the groups of the students with work experience and the ones with no work experience.The employability skills are also the prey of the perception on the grounds of gender. The survey has been conducted in the period of year 2020 in few selected districts of Western Uttar Pradesh of India. The survey findings are as follows:

\section{Employers Size Demographic statistics:}

The count of respondents for the survey was 65.Their demographic details follow as below:

\section{Employer size Demographic statistics}

Table 1:-Size of the Employers

Classification of Employers Based on the.

\begin{tabular}{|l|l|l|c|}
\hline \multicolumn{2}{|c|}{ Employer Size } & No. & No. $(\%)$ \\
\hline 1 & Large(10000and >) & 10 & 14.29 \\
\hline 2 & Medium(5000 to10000) & 18 & 28.57 \\
\hline 3 & Small(100 to 5000) & 37 & 57.14 \\
\hline \multicolumn{2}{|c|}{ Total } & 65 & 100 \\
\hline
\end{tabular}

The small organizations were the majority respondents (around 57.14 percent) followed by the medium organizations (around 28.57 percent).Rest14.29 percent participants were from large organizations:

\section{Gender Wise Experience:}

Table 2: Gender-wiseExperience

\begin{tabular}{|c|c|c|c|c|}
\hline Experience & Male & Female & Total & Total $(\%)$ \\
\hline $4-6$ & 4 & 8 & 12 & $34.29 \%$ \\
\hline $6-8$ & 6 & 9 & 15 & $42.86 \%$ \\
\hline $8-10$ & 2 & 3 & 5 & $14.29 \%$ \\
\hline$>10$ & 3 & 0 & 3 & $8.57 \%$ \\
\hline Total & 15 & 20 & 35 & $100.00 \%$ \\
\hline
\end{tabular}

The software professionals and the human resource personnel selected by the author all had a 4 year experience of working in the software sector. Respondents with the 4-6yearsofworkexperiencecategory were $34 \%$; with the experience of 6-8 years were $42.86 \%$; with the experience of $8-10$ years recognized as $14.27 \%$; and $8.57 \%$ were having experience of morethan10years.

\section{Descriptive statistics:}

Age and Gender wise Demographic statistics of the Graduates:

Table 3:Age and Gender wise

The major share (82.2 percent) belongs to 20-22 year. Among them 20 male and 50

\begin{tabular}{|c|c|c|c|c|}
\hline AGE & FEMALE & MALE & Total & Total(\%) \\
\hline 20 & 24 & 13 & 37 & $41.11 \%$ \\
\hline 21 & 6 & 9 & 15 & $16.67 \%$ \\
\hline 22 & 12 & 10 & 22 & $24.44 \%$ \\
\hline 23 & 3 & 2 & 5 & $5.56 \%$ \\
\hline 24 & 2 & 2 & 4 & $4.44 \%$ \\
\hline 25 & 3 & 1 & 4 & $4.44 \%$ \\
\hline 26 & 0 & 1 & 1 & $1.11 \%$ \\
\hline 27 & 0 & 2 & 2 & $2.22 \%$ \\
\hline Total & 50 & 40 & 90 & $100.00 \%$ \\
\hline
\end{tabular}
respondents were from the age group of 23-25 years and the remaining 3.33\% were in the age group of 26-27 years.

\section{Education Medium wise Demographic statistics of the Graduates:}

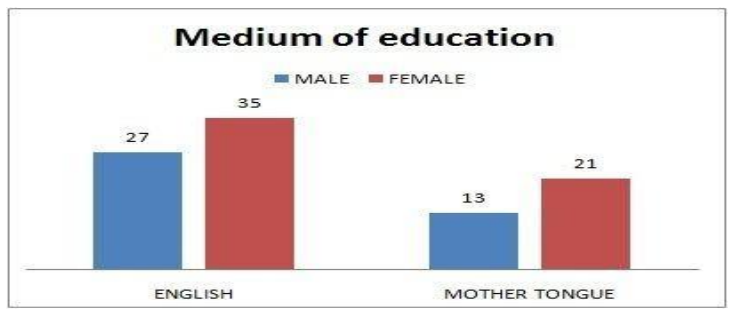

Figure 1:Education Medium

Among the candidates the major portion of the survey was shared by the ones studying in the English-medium school (around $68.89 \%$ )and the remaining $31 \%$ 
accomplished their formal education in their mother tongue. The ones who didn't do their formal education without English medium account for $67 \%$ on the males' side and $71 \%$ on the females'. The students who did complete their education in their mother tongue, both male and female include $(32.50 \%)$ and $(42 \%)$ respectively.

Work experience-Gender wise Demographic statistics:

The participants who had the work experience were very less in number(15.56\%).A significant portion of respondents didn't have any work experience.The figures gives a picturesque description of the perception that the newbie graduates have towards the employability skills.The figure 2 demonstrates thework-experience wise demographicstatisticsofthe

graduate.Amidst only 8 out of 40 boys respondents have the work experience which makes up the percentage of work experience of $20 \%$.Considering the case of females the data only shows the 6 of them being working making the percentage $12 \%$.

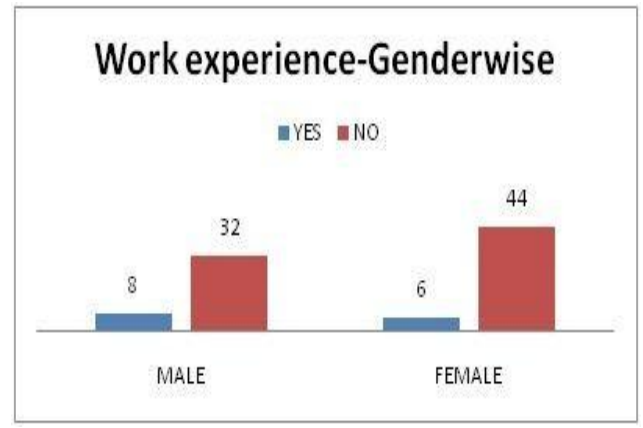

Figure 2:Work experience-

GenderwiseDemographicstatistics

\section{Educational Qualification wise} Demographic Statistics:
Table 4:Qualification of Education

\begin{tabular}{|l|l|l|l|l|}
\hline \multicolumn{1}{|r|}{ Qualification } & Girls & Boys & Total & Total(\%) \\
\hline B.E. & 21 & 24 & 45 & $50.00 \%$ \\
\hline B. Tech & 22 & 9 & 31 & $34.44 \%$ \\
\hline M.E. & 1 & 7 & 8 & $8.89 \%$ \\
\hline M. Tech. & 6 & 0 & 6 & $6.67 \%$ \\
\hline Total & 50 & 40 & 90 & $100.00 \%$ \\
\hline
\end{tabular}

Around $50 \%$ of the total respondents from the final year were aspire the $\mathrm{BE}$ and $\mathrm{B}$ tech degrees.The total share of the post-graduates in pie of respondents was $15.56 \%$.Around $15.5 \%$ of the respondents were pursuing the $\mathrm{M}$ Tech and M. E. like degrees.

\section{Most recognized Ten Employability skills} among Employer and Graduate students:

\begin{tabular}{|l|r|l|l|r|r|}
\hline Students & Mean & SD & Skills & Mea & S.D \\
\hline Skills & 4.78 & 0.69 & Reliability & 4.87 & $\begin{array}{r}0.8 \\
8\end{array}$ \\
\hline Basiccomputerskills & 4.75 & 0.66 & Integrity & 4.45 & $\begin{array}{r}0.9 \\
3\end{array}$ \\
\hline Technical skills & 4.73 & 0.66 & Teamwork & 4.41 & $\begin{array}{r}0.8 \\
8\end{array}$ \\
\hline Useofmoderntools & 4.71 & 0.64 & Willingnesstolearn & 4.4 & 0.9 \\
\hline Advancedcomputerskills & 4.65 & 0.59 & Entrepreneurship & 4.35 & $\begin{array}{r}0.8 \\
6\end{array}$ \\
\hline Systemdesign & 4.4 & 0.71 & Self-discipline & 4.26 & $\begin{array}{r}0.7 \\
9\end{array}$ \\
\hline Communication & 4.2 & 0.62 & Communication & 4.26 & $\begin{array}{r}0.9 \\
3\end{array}$ \\
\hline Responsibility & 4.11 & 0.69 & Self-motivated & 4.22 & 0.6 \\
\hline Verbalcommunication & 4.1 & 0.68 & Flexibility & 4.15 & 0.9 \\
\hline Applicationofknowledge & & & Understand/takeDir & & 0.9 \\
\hline & 4.1 & 0.77 & ection & 4.14 & 6 \\
\hline
\end{tabular}

Table 5:Most recognized Ten Employability Skills:

All the stats clearly demonstrate that much of the importance is given to the behavioral skills by the employers while the students still consider developing the technical skills over the behavioral ones.The skills which topped in the employers list like reliability, teamwork etc. do not find a place in the students' lists. The difference perception clearly 
calls for the need to aware our students to buckle up with the behavioral giving lesser attention towards the technical ones.

\section{Gap in Perception of Employer and job seekers (graduates):}

The results from the mean score rating of the job seekers (students)\& the employers and the discrepancy score rating (students rating - employees rating) were collected. The data is mentioned in figure below. There were biggest discrepancies(1.71)in empathy skills,(1.32) in integrity,(1.52) in reliability, willingness to learn,(1.40) in knowledge in contemporary issues and (1.00) in the advanced computer skills. The figure below clearly depicts the gap in opinions.

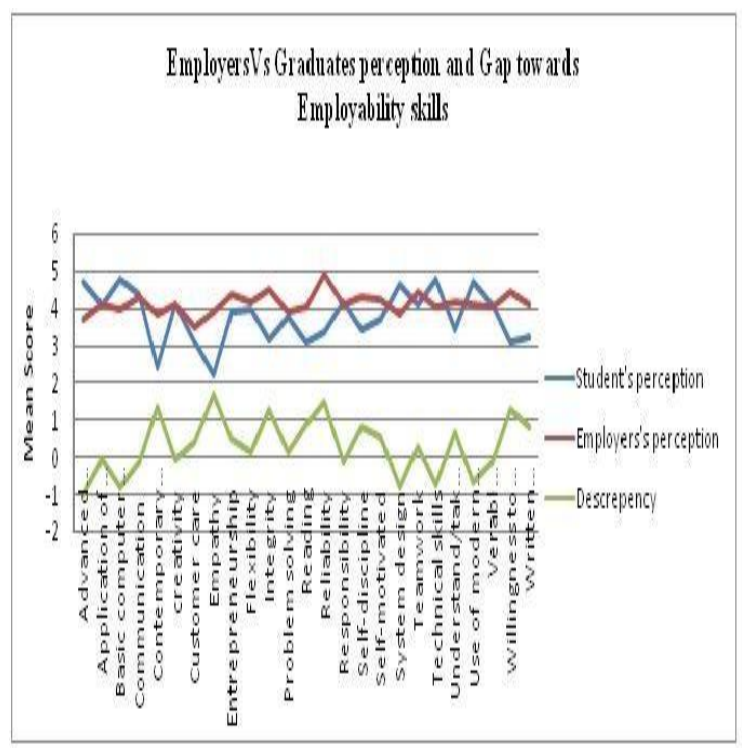

Figure: Gap in perception of Employer and employees

Gender wise Differences in skill of Graduates:

The following results were obtained by calculating the ANOVA of both the sides of gender. There seems to be no significant difference among the rating of the male and females regarding the core employability skills.Only integrity (0.1) stands out as the only attribute which shows the disparity in the rating. The participants reported with significant differences (0.01)in the professional skills i.e. Creativity, (0.01) in problem- solving, (0.02) in knowledge in contemporary issues and (0.01) in customer service, communication and technical skills. However there are three of the technical skills which hold a majorly different rating on the candidates' side viz., 0.01 in analysis and interpretation of data, 0.0 in basic computer skills and 0.03 in advanced computer skills.

\section{Work Experience wise difference in skill of Graduates:}

The students show a major difference on the grounds of having or not having the work experience. Both the categories hold a significant difference in the rating regarding self-motivation (0.02), understand and take decisions (0.03), integrity(0.02), (Core employability skills). The notable point is that these categories hold the top priority in the employers' choices. The computer service skill beholds the difference in the rating in terms of professional skills. The basic Computer skills (Communication and technical) also hold up the discrepancy. The reason being is that there is a difference in the perception that the graduates with and without the work experience have the skill which tops the graduates' list is the basic computer skills.

\section{Conclusion:}

The survey clearly enlightens the need of spreading the useful information to the graduates of the nation about the needed employability traits required by the international job market. The graduates cannot only be blamed for this very cause. 
The curriculum needs to be updated periodically for the sake of catering to the demands of the industry. Additionally, the minds of the young graduates need to be prepared regularly through long and sustainable plans so as to raise-up their bars for getting their place values in the global job market. For this the required is to initiate the industry-academia contract. This ensures the continuous global supply of talented workforce. The survey also throws light on the fact that the workexperience holders are far more aware than those who do not have any workexperience. The workers will only then be able to give their $100 \%$ input when their skills and application of knowledge are enhanced through various ways discussed above and at this hour of need only this is required; to maintain the supply chain of talent to the global job market.

\section{References:}

1. Andreas Blom, H.S.(2011). "Employability and Skill Set of Newly graduated Engineers in India". World Bank.

2. Atkins, M. J. (1999). "Oven ready and self-blasting: taking stock of employability skills. Teaching in Higher education, Vol4No2,pages26778.

3. Azami,zaharim, e. (2009). "Employers perception towards engineeringEmployabilityskillsinAsia. WSEASTransactionsonadvancesinEng ineering education,issue 6,vol.3,pp306-315.

4. Büth et al (2017) Bridging the qualification gap between academia and industry in India. Proc Manuf 9:275-282

5. Bostonconsultinggroup, (2011), Globaltalentrisk-sevenresponses.

6. Busse,R.(1992)."Thenewbasics:today'semployerswantthreeRandso
muchmore".VocationalEducationalJou rnal,Vol.67,No.5,PP24-25.

7. Chaita MV (2016) Developing graduate employability skills: your pathway to employment. Universal, Boca Raton, USA

8. DepartmentofEconomicand SocialAffairs

(2002), WorldPopulationAgeing19502050,

PopulationsDivision,Unitednations

9. DigitalAutomationandtheNewWorkfor ce(April2000).TheProgressivePolicyIn stitute,BostonConsultinggroup.

10. Dorsey I (2004) Soft skills for hard times: a handbook for high achiever. Xlibris Corporation, United States of America

11. Employability skills for Australian industry;(2001) Literaturere view and framework development; Melbourne: ACER

12. Forbes, B. K. (2004). "Student employability profiles in Engineering, Enhancing student employability coordination team "The higher education academy.

13. Hargis KB (2011) Career and technical education program alignment with local workforce needs (Ed.D. dissertation). Eastern Kentucky University (UMI No. 3488204)

14. Harvey,L.(2000)."Newrealities:therela tionshipbetweenhighereducation and employment.Territoryeducationandma nagement,Vol.6.pp3-17

15. HassanB,M.Z.(2007),Futureofenginee ringeducationinMalaysia,Ministryofhi ghereducationMalaysia.

16. HillageJ,P.E.(1999)."Employability:developingaframeworkforpolicyanalys is'. DFEE.

17. Keller S, Parker CM, Chan C (2011) Employability skills: student perceptions of an IS final year capstone subject. ITALICS 10(2):415 
18. Knight,P.Y.(2002),"Employabilityand goodlearninginhighereducation",Teach ing inHigherEducation, Vol.8.No.1,pp316.

19. Mckinsey-NASSCOM (2005),Talent shortage survey

20. Nguyen Danh Nguyen, Y. Y. (2005), University education and employment in Japan students' perception on employment attributes and implications for university education. Emerald groupPublishing,202-212

21. Noe RA, Hollenbeck JR, Gerhart B (2015) Fundamental of human resource management. McGraw-Hill, New York

22. Omar MK, Bakar AR, Rashid AM (2012) Employability skill acquisition among Malaysian community college students. J. Soc. Sci. 8(3):472-478. https://doi.org/10.3844/jssp.2012.472. 478

23. Saira A (2019) The friendly hire: why soft skills are essential in the workplace.

https://www.thehindu.com/education/c areers/the-friendly-hire-why-softskills-are-essential-in-theworkplace/article26408089.ece. Accessed 18 Dec 2019

24. UNPopulationDivision, (2009), Replacementmigration.

25. UnitedNations(2009), Worldpopulation ageing. 